\title{
Estudo comparativo entre o concreto autoadensável e o concreto convencional vibrado em obra vertical
}

\author{
Comparative study between the self-compacting concrete \\ and conventional vibrated concrete in vertical \\ constructions
}

\section{Ada Catarina Soares de Sena Costa Antonio Eduardo Bezerra Cabral}

\section{Resumo}

${ }^{1}$ Ada Catarina Soares de Sena

Costa

${ }^{1}$ Universidade Federal do Ceará Fortaleza - CE - Brasil https:// orcid. org/ 0000-0002-6178-5310

${ }^{2}$ Antonio Eduardo Bezerra Cabral ${ }^{2}$ Universidade Federal do Ceará Fortaleza - CE - Brasil

Recebido em 10/09/18 Aceito em 10/03/19

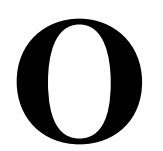

uso do concreto autoadensável (CAA) tem aumentado gradualmente no Brasil, embora seu uso seja mais restrito em obras verticais. Vantagens do CAA são apontadas na literatura, tais como a diminuição do tempo de concretagem e do número de trabalhadores, contudo poucos dados numéricos comparativos com o concreto convencional vibrado (CCV) estão disponíveis. Assim, o objetivo deste artigo é fazer uma análise comparativa entre essas duas tecnologias em uma obra de edificação vertical. Dados de ruído, custos, tempo de concretagem, quantitativo de mão de obra e de equipamentos e ferramentas foram levantados durante as concretagens. Esses dados foram transformados em indicadores para efeito de comparação entre as duas tecnologias. Em relação ao CCV, o CAA propiciou melhoria da produtividade da mão de obra em $60,7 \%$, com uma taxa de concretagem $46,1 \%$ superior, além de reduzir o ruído da obra em $10,6 \%$, a quantidade de mão de obra em $42,5 \%$ e o quantitativo de equipamentos e ferramentas em $50 \%$. Contudo, o CAA apresentou custo maior que o CCV em $8,8 \%$, o que provocou sua inviabilidade de uso ao se considerarem somente os custos diretos.

Palavras-chave: Concreto autoadensável. Concreto convencional vibrado. Ruído na construção. Custos diretos. Produtividade.

\begin{abstract}
The use of self-compacting concrete (SCC) is gradually increasing in Brazil, although in vertical buildings its use has been more limited. The literature points out the advantages of SCC, such as decreases in concreting time and labor. However, few numerical data comparing SCC with conventional vibrated concrete (CVC) are available. Hence, the aim of this article is to make a comparative analysis between the two technologies in a vertical building. Data on noise, costs, concreting time, quantitative labor and machinery and tools were obtained. These data were transformed into indicators for comparison between the two technologies. With regard to the CVC, SCC provided a $60.7 \%$ improvement in labor productivity, with a $46.1 \%$ higher concreting rate, reducing construction noise by $10.6 \%$, quantity of labor in $42.5 \%$ and the number of equipment and tools by $50 \%$. However, SCC presented a higher cost than the CVC in $8.8 \%$, which caused its infeasibility of use when considering only the direct costs.
\end{abstract}

Keywords: Self-compacting concrete. Conventional vibrated concrete. Noise in construction. Directs costs. Labor productivity.

COSTA, A. C. S. de S.; CABRAL, A. E. B. Estudo comparativo entre o concreto autoadensável e o concreto convencional 289 vibrado em obra vertical. Ambiente Construído, Porto Alegre, v. 19, n. 4, p. 289-301, out./ dez. 2019. ISSN 1678-8621 Associação Nacional de Tecnologia do Ambiente Construído. 


\section{Introdução}

No Brasil, o interesse pelo concreto autoadensável (CAA) vem crescendo, o que tem aumentado seu uso em obras correntes e especiais, sendo mais comum em empresas de pré-fabricados (TUTIKIAN et al., 2006; NUNES et al., 2009). Contudo, o CAA em obras verticais ainda é pouco utilizado no Brasil, principalmente devido ao maior custo do material. Todavia, acredita-se que os benefícios trazidos pelo CAA tornam o custo final da obra menor, uma vez que são reportados ganhos de produtividade, devido à rapidez na execução da concretagem e ao menor envolvimento de mão de obra e equipamentos (TUTIKIAN; DAL MOLIN, 2015).

Os trabalhos de Faria (2008) e Serra (2015) apresentam dados que constatam a viabilidade técnica no uso do CAA em obras verticais, como redução da mão de obra e do tempo de lançamento do concreto da ordem de $50 \%$. No estrangeiro há também relatos dessas reduções e da viabilidade da substituição do CCV pelo CAA (DOMONE, 2006; RITCH et al., 2017). Contudo, não se tem notícia de um estudo ordenado que traga luz sobre os ganhos de produtividade e sobre a redução do custo da mão de obra e do custo de máquinas e equipamentos, entre outros indicadores da concretagem.

Do ponto de vista do atendimento de propriedades do concreto no estado endurecido, o CAA pode ser mais durável que o CCV, devido a sua maior compacidade, função do maior teor de finos, com redução da permeabilidade, porosidade, coeficiente de difusão de íons cloro, entre outras propriedades, o que demonstra viabilidade técnica no uso dele (CALADO et al., 2015).

Então, o objetivo do presente artigo é analisar o uso do concreto autoadensável em obras de edificações verticais executadas em Fortaleza, CE, por meio de indicadores, e compará-lo com o concreto convencional.

\section{Concreto autoadensável}

Devido à escassez de mão de obra qualificada e de problemas relativos à durabilidade das construções, surgiu no Japão a ideia de se utilizar um concreto que fosse capaz de se compactar em todos os cantos da forma somente pela ação de seu próprio peso, sem a necessidade de compactação vibratória externa (OKAMURA; OUCHI, 2003). Em 1988, surgiu então o primeiro protótipo do CAA (GOMES; BARROS, 2009).

Para ser considerado como tal, o CAA deve ser capaz de alcançar três propriedades simultaneamente: fluidez, habilidade passante $\mathrm{e}$ resistência à segregação (EUROPEAN..., 2002). O CAA pode ser utilizado em qualquer tipo de estrutura, de forma a permitir a moldagem de estruturas com formas complexas e/ou com altas taxas de armaduras (CAVALCANTI, 2006).

Dessa forma, o CAA é considerado uma evolução do concreto convencional (CCV), por ter uma série de vantagens importantes para a indústria da construção (GOMES; BARROS, 2009). Conforme Skarendahl e Petersson (1999), o CAA provou oferecer melhorias significativas no ambiente de trabalho e no desempenho, além de melhorias na redução do tempo de construção e custos, incentivando fortemente o envolvimento industrial.

Os materiais empregados na produção do CAA são os mesmos comumente usados nos CCV, contudo a composição final da mistura e suas características no estado fresco são diferentes (ASLANI; NEJADI, 2012). Na composição do CAA empregam-se mais materiais finos do que no CCV, geralmente em quantidades superiores a $420 \mathrm{~kg} / \mathrm{m}^{3}$ do concreto. Quando a resistência característica do concreto é da ordem de $40 \mathrm{MPa}$ ou superior, todos os finos são materiais cimentícios ou pozolânicos, contudo, para concretos de menores resistências, há a necessidade de haver materiais inertes, tais como fíler calcário, na composição dos finos do CAA.

Outra premissa para a produção do CAA é o uso de aditivos dispersantes de grande eficiência. Os aditivos mais indicados para o CAA são os policarboxilatos (aditivos de terceira geração), por permitirem maior dispersão das partículas de cimento. Esses aditivos propiciam também a produção de concretos autoadensáveis de alto desempenho, uma vez que permitem o uso de menos água para fluidificar a pasta, melhorando características de durabilidade do concreto (TUTIKIAN; DAL MOLIN, 2015). Em caso de necessidade de se aumentar a viscosidade da pasta do concreto, pode-se agregar ainda um aditivo modificador de viscosidade (REPETTE, 2011).

Para medir e avaliar as três propriedades do CAA já citadas (fluidez, habilidade passante e resistência à segregação), uma gama de ensaios foi desenvolvida, pois nenhum ensaio por si só é capaz de avaliar todos esses parâmetros (EUROPEAN..., 2005). A norma brasileira que estabelece os requisitos para classificação, controle e aceitação do CAA no estado fresco, e que define e estabelece as classes de autoadensabilidade é a NBR 15823-1 (ABNT, 2017b). Segundo essa norma, os requisitos específicos para os CAA dependem do tipo de aplicação a que se destinam, além das condições de confinamento relativas à geometria do elemento de 
concreto, do tipo de equipamento a ser utilizado para o lançamento (bomba, caçamba, grua) e da importância do acabamento requerido. A norma especifica ainda ensaios a serem realizados no CAA no estado fresco, devendo ser realizada uma combinação entre eles para caracterizar completamente o concreto: slump-flow, para avaliar fluidez e escoamento; $T_{500}$ e funil $\mathrm{V}$, para avaliar a viscosidade plástica aparente; anel J, caixa L e caixa U, para avaliar a habilidade passante; coluna de segregação e método da peneira, para avaliar a resistência à segregação. O CAA difere do CCV primordialmente em seu estado fresco, por isso necessita ser avaliado com esses ensaios específicos.

No estado endurecido, os ensaios realizados no CAA são exatamente os mesmos realizados no CCV. Maior conteúdo de finos, maior presença de misturas redutoras de água e a limitação do tamanho máximo do agregado graúdo em relação ao CCV afetam o comportamento do CAA no estado endurecido (ASLANI; NEJADI, 2012). Conforme Bonen e Shah (2004), as propriedades do CAA variam em função das formulações utilizadas, contudo a literatura tem mostrado que suas propriedades mecânicas têm se mostrado equivalentes ou até mesmo melhores que as propriedades correspondentes do CCV.

\section{Sistema de indicadores}

Para manter a competitividade, as empresas acabam incorporando novos processos ou tecnologias, porém, muitas vezes, não sabem como medir se esses novos processos ou tecnologias trouxeram melhorias em seus produtos. Mensurar se um novo processo ou dada tecnologia é melhor do que outro é usualmente realizado por meio de indicadores. Existem vários indicadores que podem ser utilizados para mensuração em sistemas construtivos, contudo a produtividade e o consumo de materiais e mão de obra são os parâmetros que dão mais subsídios para a tomada de decisão sobre qual tecnologia deve ser empregada (LANTELME; TZORTZOPOULOS; FORMOSO, 2001).

Um indicador de produtividade bastante utilizado na construção civil é a razão unitária de produção (RUP). Segundo Souza (2000), a RUP diz respeito à quantidade de mão de obra (homens-hora) necessária para se produzir uma unidade da saída em estudo (por exemplo, metros cúbicos de concreto acabado ou metros quadrados de revestimento de argamassa). Ela é representada pela Equação (1), sendo o indicador mais direto para medição da produtividade da mão de obra. Quanto maior a RUP, menor a produtividade.

RUP $=$ Hh/QS

Eq. 1
Onde:

Hh = homens-hora despendidos na execução do serviço; e

QS = quantidade de serviço executado pela mão de obra em determinado tempo.

Deve-se levar em consideração para o cálculo da RUP a quantidade “líquida” de serviço executado (por exemplo, para o caso de um revestimento, não se considera a área das aberturas) e o tempo em que os operários estiveram disponíveis para o trabalho, seja esse tempo produtivo ou improdutivo (PALIARI; SOUZA, 2008).

É importante ressaltar as classificações da produtividade quanto à abrangência (tipo de mão de obra utilizada) e quanto ao intervalo de tempo relacionado às entradas e saídas. Quanto à abrangência, a RUP pode ser oficial (considera os oficiais diretamente envolvidos na produção), direta (além dos oficiais, incluem-se os ajudantes envolvidos diretamente com a produção) ou global (considera toda a mão de obra relacionada com o serviço) (PALIARI, 2008).

Especificamente para mensurar a velocidade de concretagem, tem-se o indicador "taxa de concretagem”, que é o volume de concreto lançado, adensado e acabado em um intervalo de tempo. A unidade típica é metros cúbicos por hora. Quanto maior a taxa de concretagem propiciada por dada tecnologia construtiva, melhor esta será (SERRA, 2015).

Outros indicadores podem ser utilizados, como a quantidade de máquinas e equipamentos que se usa para se produzir determinado serviço ou produto (isso é particularmente importante porque, com o uso de uma tecnologia que utilize menos máquinas e equipamentos, a empresa pode reduzir o investimento na compra ou aluguel desses itens, bem como no treinamento de sua mão de obra para utilizá-los); o nível de ruído gerado nas atividades de produção, reduzindo o risco de acidentes e afastamentos, bem como transtornos com a vizinhança; e, por fim, o indicador financeiro, que é o custo do serviço ou do produto pronto.

\section{Método de pesquisa}

Um estudo de caso do uso do concreto autoadensável (CAA) em obra vertical foi realizado em uma obra de uma torre comercial, composta de dois subsolos, térreo e mais doze pavimentos. Na concretagem da laje, nervurada e protendida, do segundo pavimento tipo (quarto teto), cujo volume total foi de $152 \mathrm{~m}^{3}$ de concreto, $28 \mathrm{~m}^{3}$ (quatro caminhões betoneira) do concreto convencional vibrado $(\mathrm{CCV})$ foram substituídos pelo CAA. O $\mathrm{f}_{\mathrm{ck}}$ 
de ambos os concretos era de $35 \mathrm{MPa}$, tendo ambos sido produzidos em central dosadora de concreto e transportados em caminhão betoneira. A Tabela 1 apresenta a composição dos traços do CCV e do CAA utilizados no estudo de caso.

No canteiro de obras, o CAA do primeiro caminhão betoneira foi submetido aos ensaios slump-flow, caixa $\mathrm{L}$ e funil $\mathrm{V}$, realizados conforme a NBR 15823-1 (ABNT, 2017b), a NBR 15823-3 (ABNT, 2017c) e a NBR 15823-5 (ABNT, 2017d) respectivamente, enquanto o CAA dos demais caminhões betoneira foi submetido apenas ao slump-flow para se ganhar tempo no lançamento dele. A Tabela 2 apresenta os requisitos estabelecidos pelos autores, baseados na NBR 15823-1 (ABNT, 2017b), conforme a aplicação dada ao CAA.

A etapa seguinte à realização dos ensaios no estado fresco consistia na moldagem de corpos de prova cilíndricos de dimensões $10 \mathrm{~cm}$ x $20 \mathrm{~cm}$, conforme procedimentos da NBR 5738 (ABNT, 2016). Os corpos de prova foram mantidos nos moldes por 24 h e, em seguida, foram desmoldados e submetidos à cura úmida (submersos em água saturada com cal) para posteriores ensaios no estado endurecido. Foram moldados um corpo de prova para o ensaio de resistência à compressão aos 4 dias (idade em que era requerida $70 \%$ da resistência característica para a realização da protensão parcial, conforme projeto estrutural) e dois corpos de prova para o ensaio aos 28 dias, para todos os caminhões betoneira, tanto do CAA quanto do CCV. Mais três corpos de prova cilíndricos de cada um dos quatro caminhões betoneira contendo CAA e dos quatro primeiros caminhões betoneira contendo CCV foram moldados para a realização do ensaio de módulo de elasticidade conforme a NBR 8522 (ABNT, 2017a).

O lançamento do CAA teve início após a aprovação do mesmo nos ensaios do estado fresco, acima já mencionados. O levantamento de dados, explicados mais adiante, se iniciou a partir do descarregamento do primeiro caminhão betoneira com o CAA e foi suspendido após a finalização do acabamento da superfície concretada. O mesmo procedimento foi adotado para a concretagem com o CCV.

O mapa de concretagem da laje em estudo está apresentado na Figura 1a. O CAA corresponde aos números de 1 a 4 , enquanto o CCV corresponde aos números de 5 a 18. A hachura escura que circunda os trechos numerados de 1 a 5 corresponde à contenção do CAA, realizada com $\mathrm{CCV}, 3$ dias antes da data em que foram realizadas as demais concretagens. Essa contenção está apresentada na Figura 1b, indicada pelas setas vermelhas.

Para realizar a comparação entre os parâmetros medidos e/ou produzidos na obra para o CAA e para o CCV, foram usados indicadores, os quais se encontram especificados no Quadro 1 e descritos de forma sucinta a seguir.

Tabela 1 - Composição dos traços do CCV e do CAA

\begin{tabular}{c|c|c}
\hline \multirow{2}{*}{ Material } & CCV & CAA \\
\cline { 2 - 3 } & Consumo $\mathbf{( k g / \mathbf { m } ^ { 3 } )}$ & Consumo (kg/. $\left.\mathbf{m}^{\mathbf{3}}\right)$ \\
\hline Cimento CP IV & 395,0 & 428,0 \\
Areia natural de rio & 713,0 & 653,0 \\
Pó de pedra (granítico) & 0,0 & 159,0 \\
Brita 12,5 mm (granítica) & 271,0 & 359,0 \\
Brita 19,0 mm (granítica) & 731,0 & 392,0 \\
Água & 188,0 & 193,0 \\
Aditivo polifuncional & 2,31 & 0,0 \\
Aditivo superplastificante à & 0,0 & 4,28 \\
base de policarboxilatos & & \\
\hline
\end{tabular}

Tabela 2 - Requisitos do CAA na obra estabelecidos conforme o Anexo A da NBR 15823-1 (ABNT, 2017b)

\begin{tabular}{c|c|c|c}
\hline $\begin{array}{c}\text { Classe de } \\
\text { espalhamento }\end{array}$ & $\begin{array}{c}\text { Classe de índice de } \\
\text { estabilidade visual }\end{array}$ & $\begin{array}{c}\text { Classe de viscosidade } \\
\text { plástica aparente (Funil V) }\end{array}$ & $\begin{array}{c}\text { Habilidade Passante } \\
\text { (Caixa L) }\end{array}$ \\
\hline $\begin{array}{c}\text { SF2 } \\
(660 \mathrm{~mm} \text { a } 750 \\
\mathrm{mm})\end{array}$ & $\begin{array}{c}\text { IEV 0 } \\
\text { Sem evidência de } \\
\text { segregação ou exsudação }\end{array}$ & $\begin{array}{c}\text { VF2 } \\
\text { s a } 25 \mathrm{~s}\end{array}$ & $\begin{array}{c}\text { PL2 } \\
\text { 0,80 com três } \\
\text { barras de aço }\end{array}$ \\
\hline
\end{tabular}


Figura 1 - (a) Mapa de concretagem; e (b) área a ser concretada com CAA, com contenções laterais com CCV

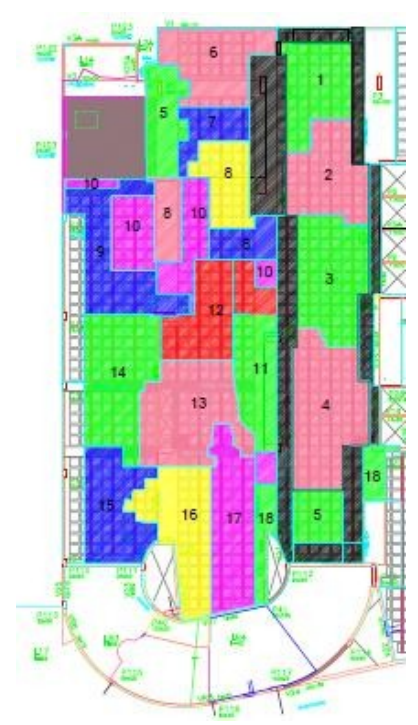

(a)

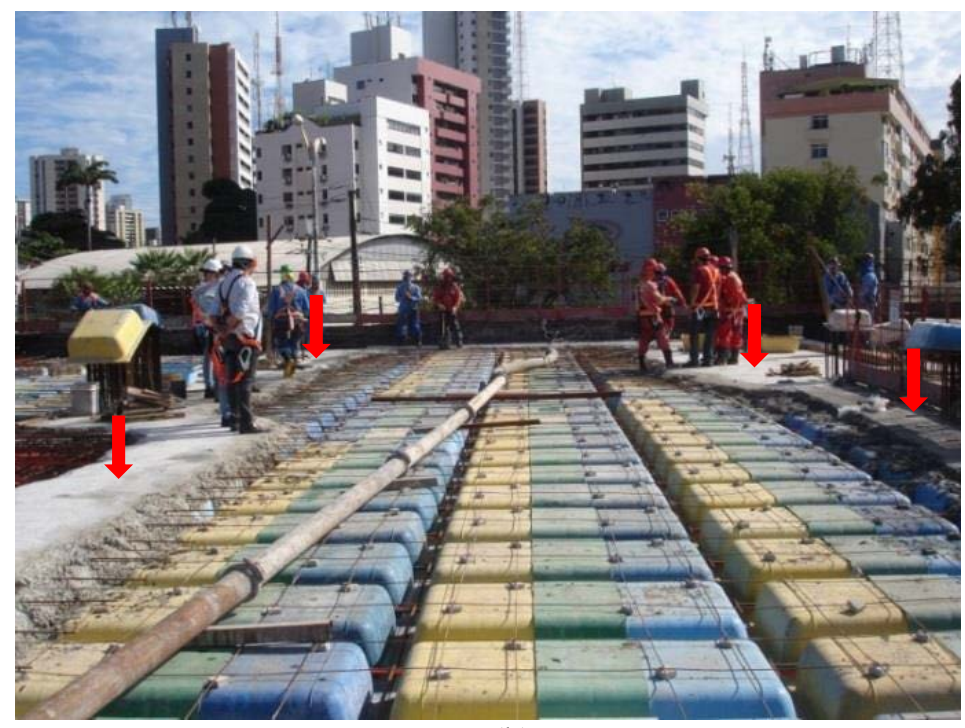

(b)

Quadro 1 - Indicadores usados

\begin{tabular}{|c|c|}
\hline Parâmetro & Indicador \\
\hline Ruído médio em dB(A) por caminhão betoneira & $\mathrm{RM}_{\mathrm{CB}}$ \\
\hline Ruído médio em dB(A) por tipo de concreto & $\mathrm{RM}_{\mathrm{TC}}$ \\
\hline Taxa de concretagem & $\mathrm{m}^{3} / \mathrm{h}$ \\
\hline Produtividade da mão de obra & $\mathrm{RUP}$ \\
\hline Custo do metro cúbico do concreto & $\mathrm{Custo} / \mathrm{m}^{3}$ \\
\hline Custo do concreto por unidade de resistência & $\mathrm{R} \$ / \mathrm{MPa}$ \\
\hline Custo total da mão de obra por hora & $\mathrm{Custo}$ \\
\hline Quantidade de equipamentos e ferramentas & $\mathrm{Q}_{\mathrm{EF}}$ \\
\hline
\end{tabular}

\section{Ruído}

O CAA dispensa o uso do vibrador de imersão para adensamento do concreto, ao contrário do CCV. Com o objetivo de ser medir o impacto da eliminação do vibrador sobre o ruído produzido na concretagem, realizaram-se medições de ruído sobre a laje que estava sendo concretada. Foi utilizado um medidor de nível de pressão sonora (decibelímetro) para a obtenção dos dados de ruído.

As medições sobre a laje, devido à movimentação dos profissionais durante a concretagem, ocorreram com o decibelímetro empunhado pelo operador, localizado tão perto quanto possível dos profissionais que manipulavam os vibradores, atentando-se para manter o aparelho a uma altura não superior a $1,50 \mathrm{~m}$. As medições ocorriam durante o descarregamento de cada caminhão betoneira e duravam 2 min. $\mathrm{O}$ medidor gravava um registro por segundo. Para a concretagem com o $\mathrm{CCV}$, as medições foram realizadas a partir do momento em que o concreto passava a ser adensado com o vibrador, enquanto para o CAA as medições ocorriam poucos instantes após o início de descarregamento do caminhão betoneira. Para cada aplicação, calculou-se o ruído médio, sendo este a média dos 120 dados obtidos.

\section{Taxa de concretagem}

Segundo Dantas (2006), a quantidade de serviço dividido pelo tempo dispendido na realização desse serviço expressa a velocidade dele. No presente estudo, essa velocidade foi chamada de taxa de concretagem $\left(\mathrm{m}^{3} / \mathrm{h}\right)$, sendo obtida pelo quociente do volume de concreto acabado, em metros cúbicos, pelo tempo dispendido para realizá-lo (T), sem as paradas, em horas. Denominou-se esse tempo de tempo líquido.

\section{Produtividade}

A produtividade da mão de obra foi medida por meio da razão unitária de produção (RUP), calculada conforme a Equação (2). Quanto à 
abrangência, a RUP utilizada foi a do tipo direta, ou seja, foram considerados os oficiais e ajudantes diretamente envolvidos no serviço durante o tempo de concretagem.

$\mathrm{RUP}_{\mathrm{MO}}=\frac{H \times T}{m^{3}}$

Onde:

RUP $_{\mathrm{MO}}=$ produtividade da mão de obra;

$\mathrm{H}=$ quantidade de homens necessários para realizar determinado volume de concretagem;

$\mathrm{T}$ = tempo da concretagem, em horas; e

$\mathrm{m}^{3}=$ volume da concretagem, em metros cúbicos.

\section{Custos}

O custo da mão de obra (Customo) é o produto do tempo da concretagem (T) pelo custo horário de cada colaborador envolvido na concretagem. O custo horário da mão de obra, com encargos sociais e outras despesas (alimentação, EPI, vale-transporte e exames), foi fornecido pela construtora, sendo este de $\mathrm{R} \$ 18,96$ para o colaborador oficial (pedreiro) e de R\$10,88 para o auxiliar (servente).

O custo do material concreto (Customaterial) também foi fornecido pela construtora, sendo o valor cobrado na nota fiscal emitida pela central de concreto. O custo do metro cúbico do CCV foi de $\mathrm{R} \$ 280,00$, e o do CAA foi de $\mathrm{R} \$ 331,00$. De fato, o CAA costuma ser mais caro que o CCV, devido à maior presença de materiais cimentícios e à alta dosagem de aditivo superplastificante em sua composição, como afirmam Cazacu, Bradu e Florea (2017).

\section{Quantidade de equipamentos e ferramentas}

Em cada concretagem avaliada, contou-se a quantidade de equipamentos e ferramentas $\left(\mathrm{Q}_{E F}\right)$ envolvidos no processo. É sabido que a mudança de tecnologia pode reduzir ou aumentar a quantidade de equipamentos e ferramentas utilizados no canteiro.

\section{Resultados e discussão}

\section{Resultados dos ensaios no concreto no estado fresco}

A Tabela 3 apresenta os resultados dos ensaios no estado fresco para cada CAA e suas respectivas classificações, de acordo com a NBR 15823-1 (ABNT, 2017b).

Conforme os resultados da Tabela 3, verifica-se que nem todos os CAA produzidos pela central de concreto e utilizados na obra enquadraram-se nas classes especificadas, mas não foram rejeitados porque essas inconformidades não comprometiam o desempenho do material. Esperava-se que no ensaio do slump-flow, por exemplo, para cada caminhão betoneira, a classe de espalhamento obtida fosse SF2. No entanto, a classe de espalhamento do CAA do último caminhão betoneira foi SF3 (com resultado acima de $750 \mathrm{~mm}$ ). O CAA, apesar de muito fluido, não apresentou segregação (vide Figura 2) e, portanto, foi lançado nesse estado sem qualquer prejuízo.

\section{Resultados dos ensaios no concreto no estado endurecido}

\section{Resistência à compressão}

Os resultados de resistência à compressão do CAA e do CCV podem ser visualizados na Figura 3. Pode-se observar que todos os CAA superaram a exigência do projeto estrutural de atingir $24,5 \mathrm{MPa}$ aos 4 dias, bem como superaram a resistência mínima de $35 \mathrm{MPa}$ aos 28 dias. A média dos resultados para o CAA superou a média para o CCV em 8,8\%. Esse resultado é coerente, uma vez que o consumo de cimento do CAA supera o do CCV em $8,4 \%$, além do que é sabido que o CAA tem maior compacidade que o $\mathrm{CCV}$, o que resulta em maiores resistências (MEHTA; MONTEIRO, 2014).

Tabela 3 - Resultados dos ensaios no estado fresco para o CAA

\begin{tabular}{c|c|c|c|c}
\hline CB & Slump-flow & Funil V & Caixa L & Classe \\
\hline $1^{\circ}$ & $693,3 \mathrm{~mm}$ & $3 \mathrm{~s}$ & 0,83 & SF2/IEV1/VF1/PL2 \\
$2^{\circ}$ & $727,5 \mathrm{~mm}$ & N.R. & N.R. & SF2/IEV0 \\
$3^{\circ}$ & $750,0 \mathrm{~mm}$ & N.R. & N.R. & SF2/IEV2 \\
$4^{\circ}$ & $790,0 \mathrm{~mm}$ & N.R. & N.R. & SF3/IEV1 \\
\hline
\end{tabular}

Notas: Legenda:

N.R. = ensaio não realizado; e

$\mathrm{CB}=$ caminhão betoneira. 
Figura 2 - Slump-flow do quarto caminhão betoneira contendo CAA

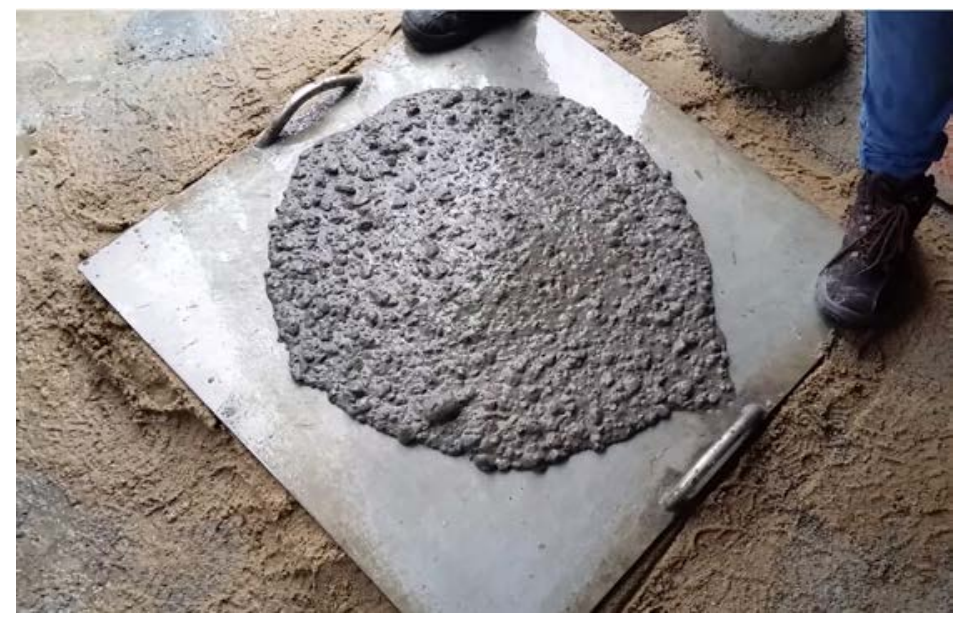

Figura 3 - Resistência à compressão dos concretos

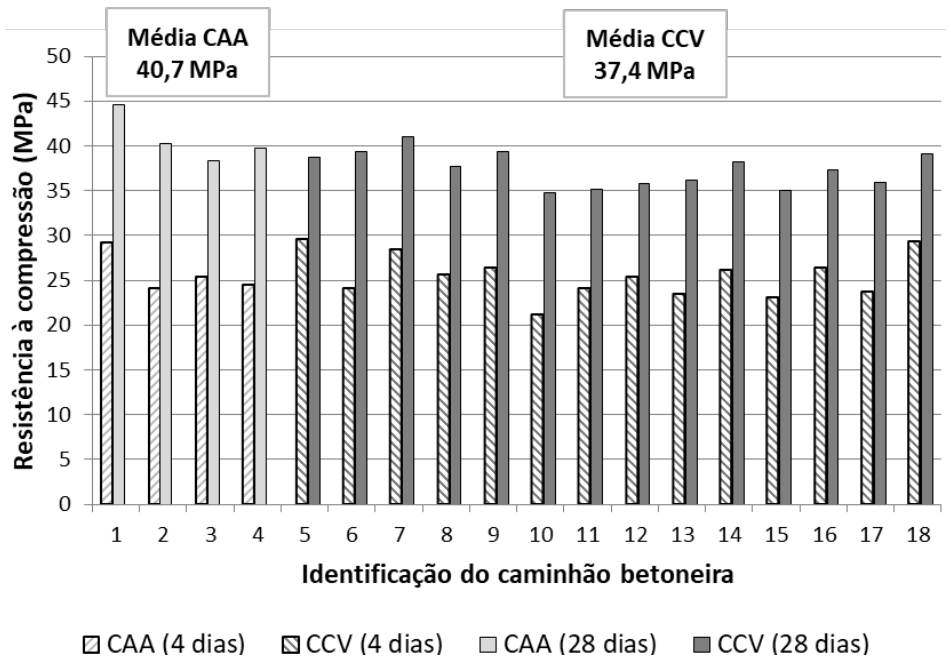

\section{Módulo de elasticidade}

Os resultados médios para o ensaio do módulo de elasticidade se encontram na Tabela 4. Pode-se observar que os valores médios do módulo de elasticidade são praticamente idênticos $(29,1 \mathrm{GPa}$ para o CAA e 29,0 GPa para o CCV).

Conforme a Tabela 1, no CAA, o conteúdo de agregados graúdos é inferior ao do CCV. Logo, seria de se esperar que seu módulo de elasticidade fosse inferior ao do CCV para uma mesma resistência, uma vez que a propriedade do módulo de elasticidade é governada pelos agregados (BONEN; SHAH, 2004). Contudo, o resultado obtido é coerente com os de Tutikian (2007). Segundo este autor, os CAA apresentam módulos de elasticidade iguais ou superiores ao CCV para resistências à compressão normais, enquanto se tornam inferiores para concretos de alta resistência (superiores a $50 \mathrm{MPa}$ ).

\section{Resultados dos indicadores coletados}

Ruído

A Figura 4 apresenta o ruído médio captado pelo medidor de nível de pressão sonora durante o descarregamento de cada caminhão betoneira. As medições realizadas durante o descarregamento dos dois primeiros caminhões betoneira contendo CAA foram perdidas por uma falha do equipamento durante as medições.

$\mathrm{O}$ ruído médio registrado no momento da concretagem com o CAA $(73,3 \mathrm{~dB})$ foi $13,8 \%$ inferior ao limite legal do ruído ocupacional, que é de $85 \mathrm{~dB}$ segundo a NR-15 (BRASIL, 1978b) e $10,6 \%$ inferior ao ruído médio produzido na concretagem com o CCV (82,0 dB), que usa o vibrador. Portanto, a ausência do ruído do vibrador de imersão contribui positivamente para a saúde e segurança não apenas dos operários que estão 
executando a concretagem, mas também para os que se encontram realizando outras funções dentro do canteiro de obras. O ruído é caracterizado como um risco físico entre os riscos ambientais considerados pela NR-9 que podem causar danos à saúde do trabalhador (BRASIL, 1978a).

\section{Tempo de concretagem e taxa de concretagem}

A Tabela 5 contempla o tempo necessário para realizar a concretagem dos trechos delimitados para cada tipo de concreto, o volume concretado em cada trecho e as taxas de concretagem. O tempo é apresentado sob a forma bruta, ou seja, quando não foram descontados os tempos de parada alheios à concretagem (por exemplo, atraso da chegada do caminhão betoneira à obra, atraso da liberação do caminhão betoneira para o descarregamento), e sob a forma líquida, quando esses tempos de parada foram descontados.

As taxas de concretagem com tempo bruto e líquido com o CAA foram $46,1 \%$ e $32,2 \%$ superiores às respectivas taxas de concretagem com o CCV. A taxa de concretagem com tempo bruto do CAA foi bastante próxima à taxa de concretagem obtida no estudo realizado por Serra (2015), também em obra vertical, que foi de $24,12 \mathrm{~m}^{3} / \mathrm{h}$, e bem superior à do estudo de Ritch et al. (2015) em lajes pré-moldadas, que foi de $8,44 \mathrm{~m}^{3} / \mathrm{h}$.

Tabela 4 - Módulo de elasticidade dos concretos

\begin{tabular}{c|c|c|c}
\hline CB & Tipo de concreto & $\begin{array}{c}\text { Módulo de elasticidade } \\
(\mathbf{G P a})\end{array}$ & $\begin{array}{c}\text { Módulo de elasticidade } \\
\text { médio (GPa) }\end{array}$ \\
\hline $1^{\circ}$ & CAA & 30,4 & \\
$2^{\circ}$ & CAA & 27,6 & 29,1 \\
$3^{\circ}$ & CAA & 30,0 & \\
$4^{\circ}$ & CAA & 28,4 & \\
\hline $6^{\circ}$ & CCV & 29,7 & 29,0 \\
$7^{\circ}$ & CCV & 31,1 & \\
$8^{\circ}$ & CCV & 26,6 & \\
$9^{\circ}$ & CCV & 28,7 & \\
\hline
\end{tabular}

Figura 4 - Ruído medido sobre a laje

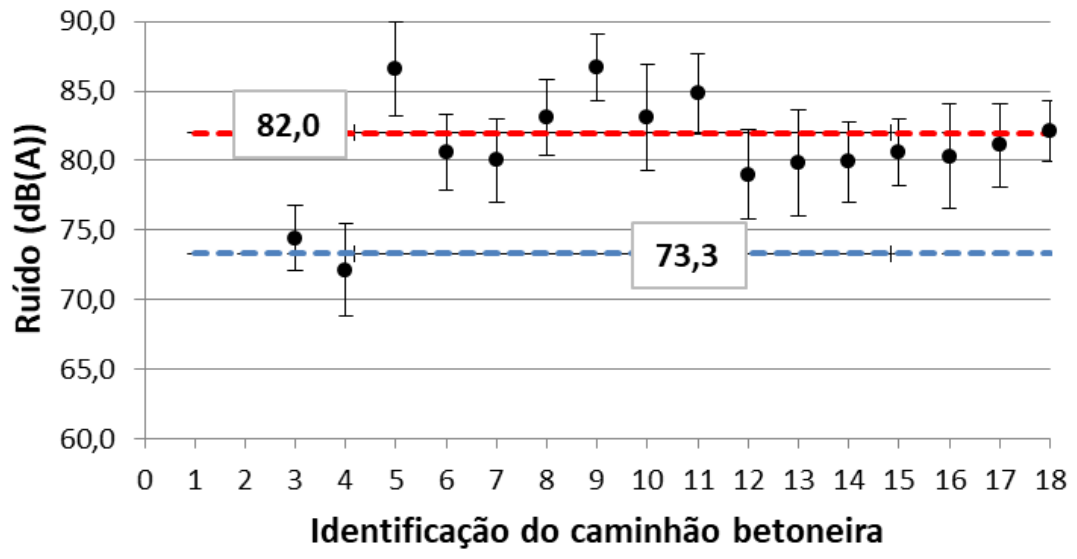

- Ruído médio/caminhão ----RMCAA ----RMCCV

Tabela 5 - Tempos e taxas de concretagem com CCV e com CAA

\begin{tabular}{|c|c|c|c|c|c|}
\hline \multirow{2}{*}{$\begin{array}{l}\text { Tipo de } \\
\text { concreto }\end{array}$} & \multirow{2}{*}{$\begin{array}{c}\text { Volume } \\
\text { concretado } \\
\left(\mathbf{m}^{3}\right) \\
\end{array}$} & \multicolumn{2}{|c|}{$\begin{array}{c}\text { Tempo de } \\
\text { concretagem (h) }\end{array}$} & \multirow{2}{*}{$\begin{array}{c}\text { Taxa de } \\
\text { concretagem com } \\
\text { tempo bruto }\left(\mathrm{m}^{3} / \mathrm{h}\right)\end{array}$} & \multirow{2}{*}{$\begin{array}{c}\text { Taxa de } \\
\text { concretagem com } \\
\text { tempo líquido }\left(\mathrm{m}^{3} / \mathrm{h}\right)\end{array}$} \\
\hline & & Bruto & Líquido & & \\
\hline & & 7,57 & 5,97 & & \\
\hline
\end{tabular}


Acredita-se que as taxas de concretagem, líquida e bruta, possam ser ainda maiores à medida que se aumente a experiência da equipe de mão de obra com o manuseio do CAA, agilizando a movimentação do mangote de distribuição do concreto e o desmonte da tubulação para realocação do mangote; que a central de concreto esteja acostumada com o processo de produção do CAA, liberando os caminhões betoneira de forma mais ágil; e que a equipe de controle tecnológico realize os ensaios no estado fresco mais rapidamente, liberando os caminhões betoneira para descarregamento mais velozmente.

O tempo necessário para realizar a concretagem de todo o volume programado utilizando apenas um dos tipos de concreto foi simulado utilizando-se a taxa de concretagem com tempo bruto. Os valores obtidos estão apresentados na Tabela 6.

Com o CAA seria possível reduzir o tempo de concretagem de toda a laje em 2,9 h (2 h e 54 min). Portanto, haveria uma economia de $31,2 \%$ no tempo de concretagem. Esses resultados podem ainda ser melhorados, como mencionado anteriormente, conforme se obtenha uma experiência maior com a produção e uso do CAA.

\section{Quantidade e produtividade da mão de obra na concretagem}

A Tabela 7 apresenta o quantitativo de operários necessários para realizar as concretagens, o volume concretado com CAA e com CCV e seus tempos brutos de concretagem, e, por fim, suas respectivas RUPMO.

Conforme os dados da Tabela 7, verifica-se que na concretagem com o CAA reduziu-se a quantidade de homens em 42,5\%, eliminando-se os funcionários que manuseavam os vibradores e os acabadores, além de reduzir os espalhadores em praticamente metade. Adicionalmente, como já mencionado, a velocidade de concretagem com o CAA é bem maior que a do CCV, o que resulta uma produtividade da mão de obra bem maior, uma vez que a RUP do CAA é inferior à do CCV (quanto menor a RUP, maior é a produtividade). Com a adoção do CAA houve melhoria de 60,7\% da produtividade da concretagem em relação ao uso do CCV.

Os valores de RUP obtidos por Serra (2015) foram de 0,20 para a primeira concretagem com CAA e de 0,17 para a segunda concretagem, valores aproximados ao obtido neste estudo de caso, o que demonstra coerência com os resultados aqui apresentados.

\section{Quantidade e produtividade de equipamentos e ferramentas na concretagem}

A Tabela 8 apresenta o quantitativo de equipamentos e ferramentas usados durante as concretagens com cada tipo de concreto. Pode-se observar que houve redução de $50 \%$ na quantidade de pás e que o vibrador e a desempenadeira não foram utilizados na concretagem com o CAA, culminando em uma redução de 50\% no quantitativo de equipamentos e ferramentas. Essa redução é devida à não necessidade da atividade de espalhamento e adensamento do CAA, devido a suas propriedades de fluidez e habilidade passante. Faria (2008) também encontrou reduções de cerca de $50 \%$ na mão de obra ao se trocar o CCV pelo CAA.

\section{Custos}

Os custos de mão de obra e do material e o custo total associados à concretagem com o CCV e com o CAA estão apresentados nas Tabelas 9 e 10 respectivamente.

Tabela 6 - Simulação dos tempos de concretagem para toda a laje com CCV e com CAA

\begin{tabular}{c|c|c}
\hline Tipo de concreto & Volume de concreto $\left.\mathbf{( m}^{3}\right)$ & Tempo de concretagem (h) \\
\hline \multirow{2}{*}{ CCV } & \multirow{2}{*}{152,0} & 9,3 \\
\cline { 3 - 3 } CAA & & 6,4 \\
\hline
\end{tabular}

Tabela 7 - Quantitativo médio e RUP da mão de obra envolvida na concretagem

\begin{tabular}{|c|c|c|c|c|c|c|c|c|}
\hline & $\begin{array}{l}\text { Lançador } \\
\text { (auxiliar) }\end{array}$ & $\begin{array}{l}\text { Vibrador } \\
\text { (auxiliar) }\end{array}$ & $\begin{array}{l}\text { Espalhador } \\
\text { (01 oficial) }\end{array}$ & $\begin{array}{l}\text { Acabador } \\
\text { (oficial) }\end{array}$ & $\begin{array}{l}\text { Total de } \\
\text { homens }\end{array}$ & $\begin{array}{c}\text { Volume } \\
\text { concretado } \\
\left(\mathbf{m}^{3}\right)\end{array}$ & $\begin{array}{c}\text { Tempo de } \\
\text { concretagem (h) }\end{array}$ & RUP $_{\text {мо }}$ \\
\hline$\overline{\text { CAA }}$ & 04 & 0 & 1,75 & 0,0 & 5,75 & 28 & 1,17 & 0,24 \\
\hline $\mathrm{CCV}$ & 04 & 02 & 3,10 & 0,9 & 10,00 & 124 & 7,57 & 0,61 \\
\hline
\end{tabular}


Tabela 8 - Quantitativo de equipamentos e ferramentas utilizados nas concretagens com CCV e com CAA

\begin{tabular}{l|c|c|c|c|c|c}
\hline & $\begin{array}{c}\text { Bomba } \\
\text { estacionária }\end{array}$ & Vibrador & Pá & $\begin{array}{c}\text { Colher de } \\
\text { pedreiro }\end{array}$ & Desempenadeira & Total \\
\hline CAA & 1 & 0 & 2 & 1 & 0 & 4 \\
CCV & 1 & 1 & 4 & 1 & 1 & 8 \\
\hline
\end{tabular}

Tabela 9 - Custo da mão de obra para a concretagem com CCV e com CAA

\begin{tabular}{|c|c|c|c|c|c|c|c|}
\hline $\begin{array}{l}\text { Tipo de } \\
\text { concreto }\end{array}$ & $\begin{array}{l}\text { Quantidade } \\
\text { de oficiais }\end{array}$ & $\begin{array}{l}\text { Quantidade } \\
\text { de auxiliares }\end{array}$ & $\begin{array}{c}\text { Custo } \\
\text { horário } \\
\text { oficial } \\
(\mathrm{R} \$ / \mathbf{h})\end{array}$ & $\begin{array}{c}\text { Custo } \\
\text { horário } \\
\text { auxiliar } \\
(\mathbf{R} \$ / \mathbf{h})\end{array}$ & $\begin{array}{c}\text { Tempo de } \\
\text { concretagem } \\
152 \mathrm{~m}^{3} \text { (h) }\end{array}$ & $\begin{array}{c}\text { Customo } \\
\text { (R\$) }\end{array}$ & $\begin{array}{c}\text { Customo } \\
\text { por } \\
\text { volume de } \\
\text { concreto } \\
\left(\mathrm{R} \$ / \mathbf{m}^{3}\right)\end{array}$ \\
\hline CAA & 1,0 & 4,75 & 18,96 & 10,88 & 6,4 & 452,10 & 2,97 \\
\hline $\mathrm{CCV}$ & 1,9 & 8,1 & 18,96 & 10,88 & 9,3 & $1.154,61$ & 7,60 \\
\hline
\end{tabular}

Tabela 10 - Custo do material para a concretagem com CCV e com CAA

\begin{tabular}{c|c|c|c}
\hline Tipo de concreto & $\begin{array}{c}\text { CustomateriaL } \\
\left(\mathbf{R} \mathbf{\$} / \mathbf{m}^{3}\right)\end{array}$ & $\begin{array}{c}\text { Customo por volume } \\
\text { de concreto } \mathbf{( R / \mathbf { m } ^ { 3 } )}\end{array}$ & $\begin{array}{c}\text { Custo total por volume } \\
\left.\text { de concreto } \mathbf{( R \mathbf { S }} / \mathbf{m}^{\mathbf{3}}\right)\end{array}$ \\
\hline CAA & 310,00 & 2,97 & 312,97 \\
CCV & 280,00 & 7,60 & 287,60 \\
\hline
\end{tabular}

Conforme os dados da Tabela 9, o custo da mão de obra para o estudo de caso em questão é de R\$2,97 por metro cúbico de CAA, o equivalente a $39,1 \%$ do custo da mão de obra do CCV, que é de R\$ 7,60 por metro cúbico de concreto. As reduções na mão de obra ao se trocar o CCV pelo CAA são coerentes com as encontradas por Geyer (2005), Repette (2007) e Serra (2015), os quais registraram reduções no custo da mão de obra superiores a $60 \%$.

Conforme informado pela construtora, o custo do metro cúbico do CAA vendido pela central de concreto é $10,7 \%$ maior que o custo do metro cúbico do CCV (R\$310,00 contra R\$280,00). Ao se somar o custo do material com o custo da mão de obra, conforme a Tabela 10, tem-se que o custo do metro cúbico do CAA (R\$ 312,97) já lançado e acabado é $8,8 \%$ maior que o custo do $\operatorname{CCV}(\mathrm{R} \$ 287,60)$ nas mesmas condições. Esse resultado é ligeiramente inferior ao encontrado por Nunes et al. (2009) numa indústria de pré-fabricados, os quais acharam o custo do CAA maior que o do CCV em cerca de $18 \%$.

Conforme os dados da Tabela 10, fica ainda evidente que o custo do material concreto influencia fortemente o custo da concretagem, sobretudo ao se usar o CAA, pois, neste caso, esse custo representou $99,1 \%$ do custo total, contra $97,3 \%$ ao se usar o CCV. Segundo Rich et al. (2015), o preço do material constitui a principal barreira para o uso do CAA. De fato, pôde-se notar que o custo do CAA elevado em relação ao CCV provoca um aumento expressivo no custo total da concretagem, mesmo com as grandes reduções de custos de mão de obra. Então, para tornar viável o uso do CAA, embora se obtenha uma boa economia com a mão de obra, o preço por metro cúbico de CAA precisa ser aproximado ao preço do CCV. Segundo os dados do estudo de caso realizado neste artigo, para o CAA se tornar economicamente viável, este deve ter um preço de no máximo $\mathrm{R} \$ 284,62$, ou seja, apenas $1,65 \%$ mais caro.

Contudo, deve-se ressaltar que outras economias não foram levadas em consideração neste estudo de caso para atestar a viabilidade do uso do CAA. A redução no tempo de concretagem, por exemplo, abre oportunidade para o adiantamento de outros serviços no canteiro de obra (melhor aproveitamento da mão de obra disponível), encurtamento do tempo de aluguel de grandes máquinas e antecipação de entrega do empreendimento (redução do risco de multas por atraso e geração de renda com aluguel/venda). O não uso de vibradores, por sua vez, gera economia de energia elétrica e prolongamento da vida útil das formas. E ainda há a provável redução de custos com manutenção e reparos futuros, em função do fato de o CAA propiciar concretos mais duráveis.

\section{Conclusões}

Diante dos resultados obtidos neste artigo, pode-se concluir que:

(a) a eliminação do vibrador pelo uso do CAA resultou em redução de $10,6 \%$ no ruído na laje, o 
que contribui positivamente para a saúde e a segurança dentro do canteiro de obra;

(b) o tempo bruto de concretagem (considerando eventuais paradas) com o uso do CAA reduziu-se em $84,5 \%$, e a taxa de concretagem com esse tempo aumentou $46,1 \%$, ou seja, com o uso do CAA se consegue concretar mais rápido que com o CCV;

(c) a quantidade da mão de obra com o CAA foi reduzida em 42,5\% em função da eliminação dos funcionários que manuseavam os vibradores e que faziam os acabamentos, além da redução dos espalhadores pela metade, e o CAA propiciou melhoria na produtividade da concretagem em 60,7\%;

(d) a quantidade de equipamentos e ferramentas usadas na concretagem com o CAA foi $50 \%$ menor que a utilizada na concretagem com o CCV, em função da redução na quantidade de funcionários envolvidos na concretagem com o CAA; e

(e) o uso do CAA propiciou redução no custo da mão de obra de 60,9\% em comparação com o custo da mão de obra com o CCV, contudo o CAA é vendido pela central de concreto $10,7 \%$ mais caro que o CCV - como o custo do material concreto é a parte mais representativa no custo da concretagem (representa 99,1\% do custo total para a concretagem com o CAA e $97,3 \%$ do custo total para a concretagem com o CCV), as reduções da mão de obra e do tempo de concretagem propiciadas pelo CAA não foram suficientes para torná-lo viável financeiramente.

Por fim, para que o uso do CAA seja viável em obras verticais, ao se considerar somente o custo do material e da mão de obra (custos diretos), faz-se necessário que o preço cobrado por metro cúbico de CAA seja próximo do preço cobrado para o CCV.

\section{Referências}

ASLANI, F.; NEJADI, S. Mechanical Properties of Conventional and Self-Compacting Concrete: an analytical study. Construction and Building Materials, v. 36, p. 330-347, 2012.

\section{ASSOCIAÇÃO BRASILEIRA DE NORMAS} TÉCNICAS. NBR 15823-1: concreto autoadensável: parte 1: classificação, controle e recebimento no estado fresco. Rio de Janeiro, $2017 \mathrm{~b}$.

\section{ASSOCIAÇÃO BRASILEIRA DE NORMAS TÉCNICAS. NBR 15823-3: concreto} autoadensável: parte 3: determinação da habilidade passante: método do anel J. Rio de Janeiro, 2017c.
ASSOCIAÇÃO BRASILEIRA DE NORMAS

TÉCNICAS. NBR 15823-5: concreto

autoadensável: parte 5: determinação da viscosidade: método do funil V. Rio de Janeiro, 2017d.

ASSOCIAÇÃO BRASILEIRA DE NORMAS TÉCNICAS. NBR 5738: concreto: procedimento para moldagem e cura de corpos de prova. Rio de Janeiro, 2016.

\section{ASSOCIAÇÃO BRASILEIRA DE NORMAS}

TÉCNICAS. NBR 8522: concreto: determinação dos módulos estáticos de elasticidade e de deformação à compressão. Rio de Janeiro, 2017a.

BONEN, D.; SHAH, S. P. The Effects of Formulation on the Properties of SelfConsolidating Concrete. In: INTERNATIONAL RILEM SYMPOSIUM ON CONCRETE SCIENCE AND ENGINEERING: A TRIBUTE TO ARNON BENTUR, 2004. Proceedings... 2004.

BRASIL. Ministério do Trabalho e Emprego. Norma Regulamentadora $\mathbf{N}^{\mathbf{0}} 9$ - Programa de Prevenção de Riscos Ambientais. Brasília: Ministério do Trabalho e Emprego, 1978a. Disponível em:

<http://trabalho.gov.br/images/Documentos/SST/N R/NR09/NR-09-2016.pdf>. Acesso em: 2 ago. 2017.

BRASIL. Ministério do Trabalho e Emprego. Norma Regulamentadora $\mathbf{N}^{\circ} \mathbf{1 5}$ - Atividades e Operações Insalubres. Brasília: Ministério do Trabalho e Emprego, 1978b.

CALADO, C. et al. Concreto Auto-Adensável (CAA), Mais do que Alternativa Ao concreto Convencional (CC). Recife: Editora da Universidade de Pernambuco, 2015.

CAVALCANTI, D. J. H. Contribuição ao Estudo de Propriedades do Concreto Auto-Adensável Visando sua Aplicação em Elementos Estruturais. Maceió, 2006. Dissertação (Mestrado em Engenharia Civil) - Escola de Engenharia, Universidade Federal de Alagoas, Maceió, 2006.

CAZACU, N.; BRADU, A.; FLOREA, A. SelfCompacting Concrete Structures: a technoeconomic analysis. Advanced Engineering Forum, v. 21, p. 624-631, 2017.

DANTAS, M. M. Proposição de Ações Para Melhoria da Produtividade da Concretagem em Edifícios Verticais. São Paulo, 2006. Dissertação (Mestrado em Engenharia) - Escola Politécnica, Universidade de São Paulo, São Paulo, 2006.

DOMONE, P. L. Self-Compacting Concrete: an analysis of 11 years of case studies. Cement \& Concrete Composites, v. 28, p. 197-208, 2006. 
EUROPEAN FEDERATION FOR SPECIALIST CONSTRUCTION CHEMICALS AND

CONCRETE SYSTEMS. Specification and Guidelines For Self-Compacting Concrete. 2002.

EUROPEAN FEDERATION FOR SPECIALIST CONSTRUCTION CHEMICALS AND CONCRETE SYSTEMS. The European guidelines for self-compacting concrete: especification, production and use. 2005.

FARIA, R. Solução Fluida. Revista Téchne, v. 132, 2008.

GEYER, A. L. B. Utilização de Concreto AutoAdensável em Estruturas de Edifícios Com Custos Inferiores ao Concreto Convencional. In: CÂMARA BRASILEIRA DA INDÚSTRIA DA CONSTRUÇÃO. $12^{\circ}$ Concurso Falcão Bauer. 2005.

GOMES, P. C. C.; BARROS, A. R. Métodos de Dosagem de Concreto Autoadensável. São Paulo: Pini, 2009.

LANTELME, E. M. V.; TZORTZOPOULOS, P.; FORMOSO, C. T. Indicadores de Qualidade e Produtividade Para a Construção Civil. Porto Alegre: Núcleo Orientado para a Inovação da Edificação, Programa de Pós-Graduação em Engenharia Civil, Universidade Federal do Rio Grande do Sul, Porto Alegre, 2001. (Relatório de Pesquisa).

MEHTA, K. P. MONTEIRO, P. J. M. Concreto: microestrutura, propriedades e materiais. 2. ed. Ibracon, 2014.

NUNES, S. et al. SCC and Conventional Concrete on Site: property assessment. Ibracon Structures and Materials Journal, v. 2, n. 1, p. 25-36, mar. 2009.

OKAMURA, H.; OUCHI, M. Self-Compacting Concrete. Journal of Advanced Concrete Technology, v. 1, n. 1, p. 5-15, apr. 2003.

PALIARI, J. C. Método Para Prognóstico da Produtividade da Mão-de-Obra e Consumo Unitário de Materiais: sistemas prediais hidráulicos. São Paulo, 2008. Tese (Doutorado em Engenharia) - Escola Politécnica, Universidade de São Paulo, São Paulo, 2008.
PALIARI, J. C.; SOUZA, U. E. L. de. Método Simplificado Para Prognóstico do Consumo Unitário de Materiais e da Produtividade da Mão-de-obra: sistemas prediais hidráulicos. São Paulo: Epusp, 2008. Boletim Técnico da Escola Politécnica da USP, Departamento de Engenharia de Construção Civil, BT/PCC/502.

REPETTE, W. L. Concreto Autoadensável. In: ISAIA, G. C. (Org.). Concreto: ciência e tecnologia. São Paulo: Ibracon, 2011.

REPETTE, W. L. Self-Compacting Concrete: a labor cost evaluation when used to replace traditional concrete in building construction. In: INTERNATIONAL RILEM SYMPOSIUM ON SELF-COMPACTING CONCRETE, 5., Ghent, 2007. Proceedings... Ghent, 2007.

RICH, D. et al. Optimising Construction With Self-Compacting Concrete. Proceedings of the Institution of Civil Engineers - Construction Materials, v. 170, n. 2, p. 104-114, apr. 2015.

SERRA, J. H. F. Avaliação da Utilização do Concreto Autoadensável em Substituição ao Concreto Convencional Em uma Obra de Edificação Vertical. Fortaleza, 2015. Dissertação (Mestrado em Engenharia Civil) - Escola de Engenharia, Universidade Federal do Ceará, Fortaleza, 2015.

SKARENDAHL, Á.; PETERSSON, Ö. SelfCompacting Concrete. In: INTERNATIONAL RILEM SYMPOSIUM, 1., 1999. Proceedings... 1999.

SOUZA, U. E. L. Como Medir a Produtividade da Mão-de-Obra na Construção Civil. In: ENCONTRO NACIONAL DE TECNOLOGIA DO AMBIENTE CONSTRUÍDO, 8., Salvador, 2000. Anais... Salvador, 2000.

TUTIKIAN, B. F. et al. Viabilidade Técnica e Econômica do Concreto Auto-Adensável em Empresas de Pré-Moldado. Concreto \& Construções, v. 34, n. 43, p. 30-35, jun./ago. 2006.

TUTIKIAN, B. F. Proposição de Um Método de Dosagem Experimental Para Concretos AutoAdensáveis. Porto Alegre, 2007. Tese (Doutorado em Engenharia Civil) - Escola de Engenharia, Universidade Federal do Rio Grande do Sul, Porto Alegre, 2007.

TUTIKIAN, B. F.; DAL MOLIN, D. C. Concreto Autoadensável. 2. ed. São Paulo: Pini, 2015. 


\section{Ada Catarina Soares de Sena Costa}

Programa de Pós-Graduação em Engenharia Civil: Estruturas e Construção Civil | Universidade Federal do Ceará | Campus do Pici, Bloco 733, Pici | Fortaleza - CE - Brasil | E-mail: adacsena@hotmail.com

\section{Antonio Eduardo Bezerra Cabral}

Programa de Pós-Graduação em Engenharia Civil: Estruturas e Construção Civil | Universidade Federal do Ceará | Campus do Pici, Bloco 710, Pici | Fortaleza - CE - Brasil | CEP 60455-760 | Tel.: (85) 3366-9607 Ramal 38 | E-mail: eduardo.cabral@ufc.br

\section{Revista Ambiente Construído}

Associação Nacional de Tecnologia do Ambiente Construído

Av. Osvaldo Aranha, 99 - 3o andar, Centro

Porto Alegre - RS - Brasil

CEP 90035-190

Telefone: +55 (51) 3308-4084

Fax: +55 (51) 3308-4054

www. seer. ufrgs. br/ ambienteconstruido

E-mail: ambienteconstruido@ufrgs.br

(c) (i)

This is an open-access article distributed under the terms of the Creative Commons Attribution License.

Estudo comparativo entre o concreto autoadensável e o concreto convencional vibrado em obra vertical 301 